\title{
Expressing Status and Correlation of ARID1A and Histone H2B on Breast Cancer
}

\author{
Yan Wu, ${ }^{1,2}$ Yan Gu, ${ }^{1}$ Shanyu Guo, ${ }^{1}$ Qiancheng Dai, ${ }^{1}$ and Wei Zhang ${ }^{1}$ \\ ${ }^{1}$ Department of Surgery, The Ninth People's Hospital, School of Medicine, Shanghai Jiao Tong University, Shanghai 200011, China \\ ${ }^{2}$ Department of Surgery, Zhoupu Hospital of Pudong District, Shanghai, China
}

Correspondence should be addressed to Wei Zhang; weizh1518@hotmail.com

Received 16 August 2015; Revised 19 December 2015; Accepted 22 December 2015

Academic Editor: Martin Sebastian Staege

Copyright (C) 2016 Yan Wu et al. This is an open access article distributed under the Creative Commons Attribution License, which permits unrestricted use, distribution, and reproduction in any medium, provided the original work is properly cited.

\begin{abstract}
ARID1A is one of the important cancer-related genes and regulates transcription of certain genes by altering chromatin structure. Inactivated mutations and decreased expression of ARID1A gene have been reported in several kinds of cancer. Histone H2B is a major component of chromatin and encoded by HIST1H2BE. The goal of the study is to evaluate expressing status of ARID1A and $\mathrm{H} 2 \mathrm{~B}$ as well as their correlation on breast cancer. Gene expression profiles of ARID1A and H2B on Oncomine database are analyzed. Tissue microarray of breast cancer was used for examination of ARID1A and H2B expression by immunohistochemistry. As a result, the disagreement of ARID1A expression was found, while HIST1H2BE expression is elevated in 4 out of 5 datasets on Oncomine database. There were 15 cases $(20 \%)$ of breast cancers that were positive for ARID1A. Fifty-eight out of 75 cases of breast cancer $(77.3 \%)$ were highly expressed for $\mathrm{H} 2 \mathrm{~B}$ protein and 17 cases $(22.7 \%)$ were low expressed for H2B protein. All cases with ARID1A expression are overlapped with $\mathrm{H} 2 \mathrm{~B}$ high expression. Among 15 cases with ARID1A and H2B coexpression, 13 are invasive ductal carcinoma and 2 are mucinous carcinoma. Our results indicate that ARID1A gene may be involved in carcinogenesis of some subtypes of breast cancer.
\end{abstract}

\section{Introduction}

ARID1A (AT-rich interactive domain 1A) is one of the important cancer-related genes by large-scale cancer genome sequencing in recent years. Mutations in the chromatin remodeling gene ARID1A have recently been identified in the majority types of cancer, such as gastric cancer, colon cancer, bladder cancer, ovarian cancer, liver cancer, and breast cancer [1-6]. In stomach cancer, ARID1A mutations result in lost expression and obtain a better prognosis $[7,8]$. However, Huang and coworkers found that mutations of ARID1A gene in primary liver cancer cause an enhanced invasiveness and metastatic ability [3]. Inactivated mutations and hypermethylation of promoter of ARID1A gene have been reported in breast cancer by several reports [9]. However, the precise mechanisms of ARID1A gene in carcinogenesis are largely unknown.

ARID1A is located on chromosome 1p35.3, a region frequently deleted in human cancers, which encodes a member of the SWI/SNF family, whose members have helicase and ATPase activities and are thought to regulate transcription of certain genes by altering the chromatin structure $[10,11]$. ARID1A has a DNA-binding domain that can specifically bind an AT-rich DNA sequence known to be recognized by a SNF/SWI complex at the beta-globin locus. The C-terminus of the protein can stimulate glucocorticoid receptor-dependent transcriptional activation. Recently, Li and colleagues found that histone $\mathrm{H} 2 \mathrm{~B}$ is a functional target of ARIDIA, which is involved in histone modifications [12].

$\mathrm{H} 2 \mathrm{~B}$ is a basic nuclear protein that is responsible for the nucleosome structure of the chromosomal fiber in eukaryotes. One report disclosed that $\mathrm{H} 2 \mathrm{~B}$ monoubiquitylation is a $5^{\prime}$-enriched active transcription mark [13]. Slowinski and coworkers noticed that there was a high correlation between H2B mRNA level and nuclear division index as well as histone labeling index in human glioma cell lines. Histone H2B mRNA level and histone labeling index may be a useful molecular predictor of the tumor response to radiation treatment in gliomas of the same histological grade [14]. Moreover, Hao and coworkers revealed that high level 
of serum histone $\mathrm{H} 2 \mathrm{~B}$ could predict a poorer prognosis of gastric cancer [15]. To clarify the possible relation of ARID1A and $\mathrm{H} 2 \mathrm{~B}$, we analyzed the expressing status of ARID1A and $\mathrm{H} 2 \mathrm{~B}$ on breast cancer.

Oncomine is a web-based microarray database. It currently contains 674 datasets including 73327 samples from different types of tumors and provides free access to all researchers. Oncomine integrates high-throughput cancer profiling data across a large volume of cancer types, subtypes, and experiments so that target expression can be assessed online [16-18]. In present study, we screened the expression status of ARID1A and HIST1H2BE (H2B encoding gene) by Oncomine database and then examined the protein expression of ARID1A and histone H2B simultaneously on tissue microarray of breast cancer.

\section{Materials and Methods}

2.1. Oncomine Database Analysis. To get the outline of the ARID1A and H2B expression pattern, we searched the ARID1A and $\mathrm{H} 2 \mathrm{~B}$ mRNA levels in human cancers using datasets from the publicly available Oncomine database (http://www .oncomine.org).

2.2. Tissue Microarray and Reagents. Tissue microarray (TMA) of breast cancer (OD-CT-RpBre01-003) was purchased from OUTDO Biotech Co., LTD. (Shanghai, China), which contains 80 cases of breast cancer who are aged from 33 to 81 years (average 55 years). Ten of them have paired adjacent normal breast tissue. Among them, 55 cases are invasive ductal carcinoma, 6 invasive lobular carcinoma, 9 mucinous carcinoma, 4 medullary carcinoma, 3 lipid-rich carcinoma, and 3 ductal carcinoma in situ.

2.3. Ethics Statement. Written informed consent in the study was obtained from all participants. The study protocol was approved by the ethics committee of OUTDO Biotech Co., LTD., Shanghai.

2.4. Immunohistochemistry for ARID1A and H2B. TMA was dewaxed and hydrated using alcohol. Antigen was retrieved by citrate buffer, and endogenous hydrogen peroxide was blocked with 3\% hydrogen peroxide solution. Mouse antihuman ARID1A monoclonal antibody (1:50, SC-32761, Santa Cruz, USA) and rabbit antihuman $\mathrm{H} 2 \mathrm{~B}$ monoclonal antibody ( $1: 1200$, ab52599, Abcam, USA) were dropped and incubated at $37^{\circ} \mathrm{C}$ for $1 \mathrm{~h}$, respectively, and then washed 3 times with $1 \mathrm{x}$ PBS for $5 \mathrm{~min}$. Then, EnVision two-step reagents (Dako) were incubated at $37^{\circ} \mathrm{C}$ for $30 \mathrm{~min}$. DAB was used for coloration, and hematoxylin was used for nuclear staining with positive signals observed as yellow or brown patches. Both ARID1A and $\mathrm{H} 2 \mathrm{~B}$ are expressed in the nucleus or nucleus/cytoplasm was judged as positive staining. In order to guarantee the reliability of the experiment, we use a previous confirmed gastric cancer as positive control and remove primary antibody as a negative control. TMA was scored according to the percentage of cells stained positively, and the intensity of the staining. The percentage of stained cells was scored on a scale of $0(<10 \%), 1(10 \%-30 \%), 2(31 \%-50 \%)$, and $3(51 \%-100 \%)$.
Stain intensity was scored on a scale of 0 (negative), 1 (weak), 2 (moderate), and 3 (strong). A cumulative staining score ranging from 0 to 9 was used for statistical analysis and was obtained by multiplying intensity scores with cell percentage scores. Total staining score was graded as weakly positive $(<4$ scores) and strongly positive (over 6 scores).

2.5. Statistical Analysis. Statistical analysis was performed by using the program package SPSS 15.0. The measurement data were analyzed by $t$-test, and numeration data were analyzed using the $\chi^{2}$ test or Fisher's exact test. Differences were considered significant at $P<0.05$.

\section{Results}

3.1. $m R$ NA Expressing Pattern of ARID1A and HIST1H2BE on Oncomine Database. In 13 datasets for ARID1A, the mRNA expression of ARID1A was differed between several datasets. ARID1A mRNA was found significantly elevated in human breast cancer tissues compared with normal tissues in datasets from TCGA, Radvanyi, Ma, Gluck, and Zhao's groups, while ARID1A mRNA was decreased in human breast cancer tissues compared with normal tissues in Sorlie, Perou, Finak, and Richardson's datasets (Figure 1(a)). However, we noticed that the cases examined in every group are very different. For instance, in Gluck's group, there are only 4 normal controls against 154 cancer cases [19-22]. There is obvious disagreement between different datasets. We searched 5 datasets for HIST1H2BE expression. The expression of HIST1H2BE was elevated in cancer compared to that in normal tissue on 4 out of five datasets (Figure 1(b)). One remaining dataset (Turashvili dataset) revealed no difference of HIT1H2BE expression between breast cancer group and normal tissue group $[19,21,23]$.

3.2. The Protein Expression of ARID1A and $H 2 B$ on Tissue Microarray. A total of 75 cases are included in the final analysis except for five shedding points from tissue arrays. The age of patients was from 33 to 81 years (average 55 years). Ten of them have paired adjacent normal breast tissue. In this group, 51 cases of tumor were primary breast cancer without metastasis and 24 cases with metastasis in axillary lymph nodes. We found weak or lost ARID1A expression in normal epithelial cells of breast. There were 60 (80\%) cases of breast cancers with negative expression of ARID1A. Only 15 cases $(20 \%)$ of breast cancers were positively expressed for ARID1A. H2B protein was expressed on normal mammary epithelium (with scores from 4 to 6). In breast cancer, 58 cases (77.3\%) were highly expressed for $\mathrm{H} 2 \mathrm{~B}$ protein (with scores from 6 to 9 ) and 17 cases (22.7\%) were low expressed for $\mathrm{H} 2 \mathrm{~B}$ protein (Figure 2). The mean score of $\mathrm{H} 2 \mathrm{~B}$ protein in breast cancer tissues was significantly higher than that in normal mammary epithelium $(P<0.05$, Figure 3(a)).

We compared multiple clinicopathological parameters with ARID1A and $\mathrm{H} 2 \mathrm{~B}$ expression. There is no significant difference between ARID1A or H2B expression with patients' age, location, histological types, and axillary lymph node status. However, we noticed that the protein expressions of ARID1A and $\mathrm{H} 2 \mathrm{~B}$ are closely related to each other $(P=0.019$, 

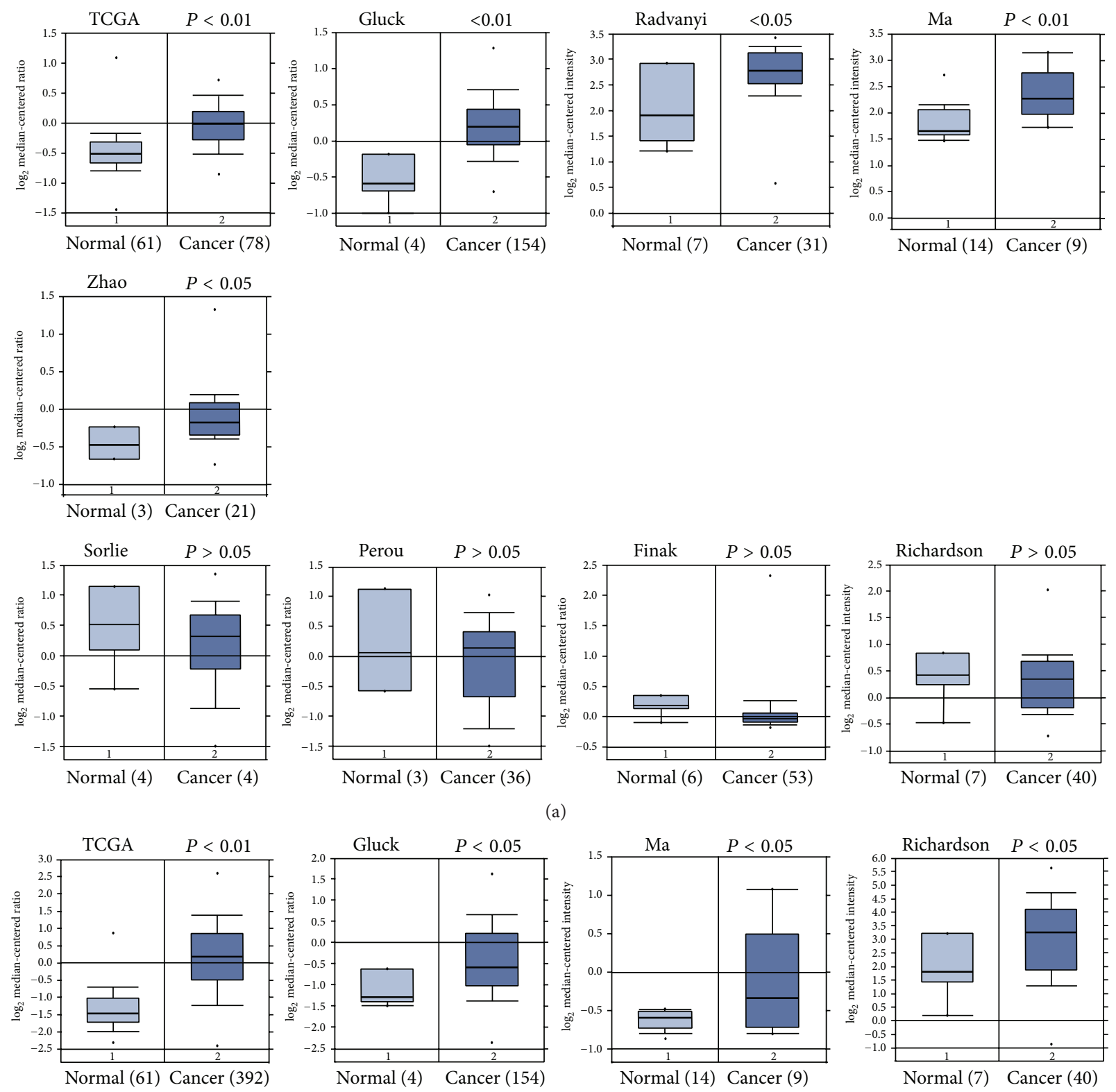

(b)

FIgURE 1: Search for ARID1A and HIST1H2BE mRNA expression of human breast cancer in Oncomine database. (a) Analysis of ARID1A mRNA levels in human breast cancer tissues on different datasets. (b) The mRNA levels of HST1H2BE of breast cancer groups are elevated in different datasets.

Table 1). In nonparametric correlation analysis, the expression of ARID1A and H2B is positively related to Spearman's $R 0.28(P=0.009)$. It suggested that the expression of ARID1A is often companied by the high expression of histone $\mathrm{H} 2 \mathrm{~B}$ in a subset of breast cancers (Figure 3(b)). Figure 4 presented expression of ARID1A and H2B on the same case of invasive ductal carcinoma in serial sections of tissue array. The positive correlation of protein expression of ARID1A and $\mathrm{H} 2 \mathrm{~B}$ was well presented (Table 2). Both ARID1A and H2B presented nucleus or nucleus/cytoplasm expressing pattern. The expression status of ARID1A and H2B in serial sections of tissue arrays was summarized in Figure 5, in which each case has two tissue points on the same line. The gray grid in the array represented strong positivity for $\mathrm{H} 2 \mathrm{~B}$ protein, while the white capitalized letter A represented positivity for ARID1A protein. All 15 cases with ARID1A expression were overlapped with the highly expressed H2B. Although there was no statistic significance between ARID1A and H2B expression with histological types, we noticed that the 13 cases with ARID1A expression belong to invasive ductal carcinoma and the remaining 2 cases are mucinous carcinoma.

\section{Discussion}

Decreased expression of ARID1A on breast cancer has been found in several studies. As to reasons, it may be caused by 

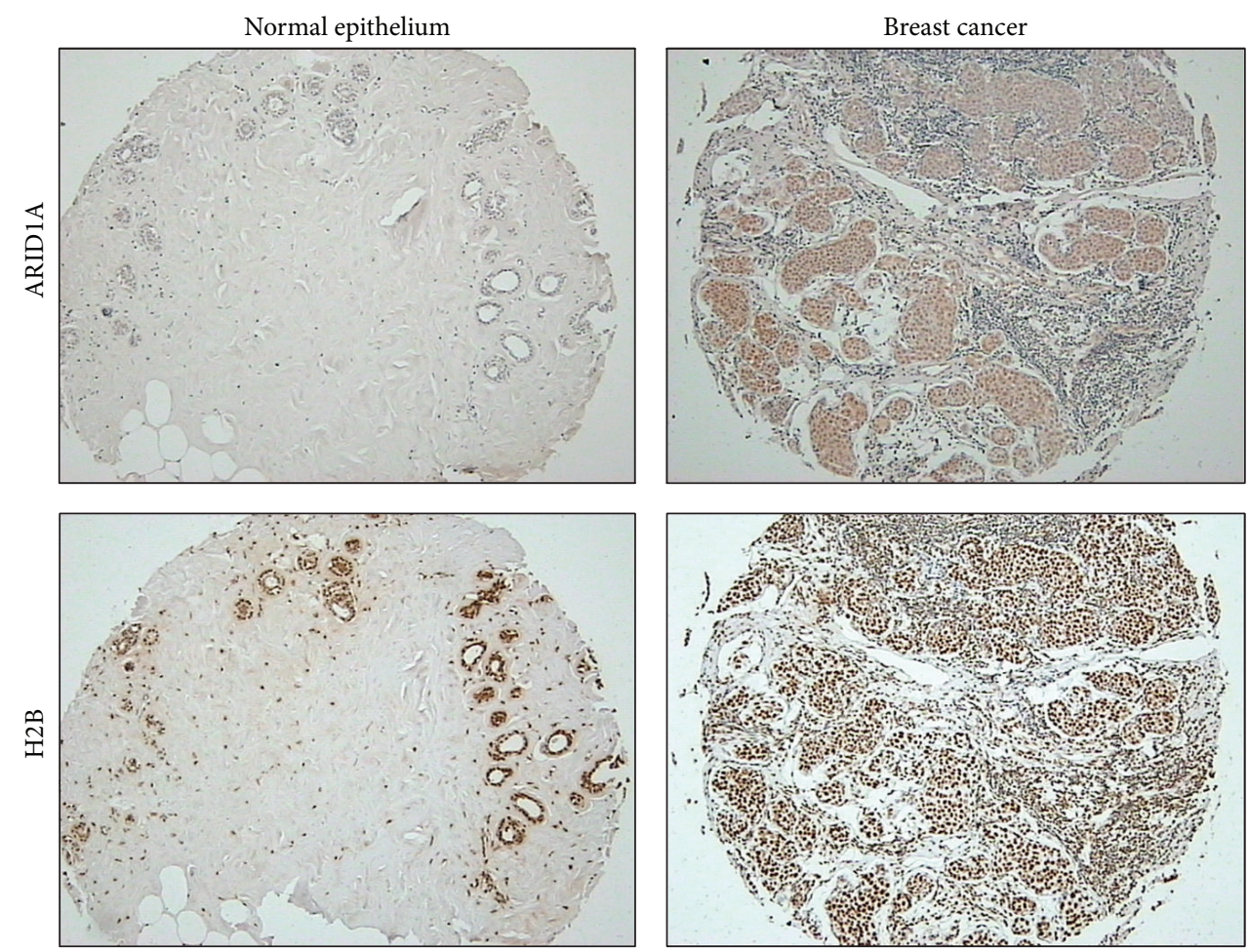

(a)
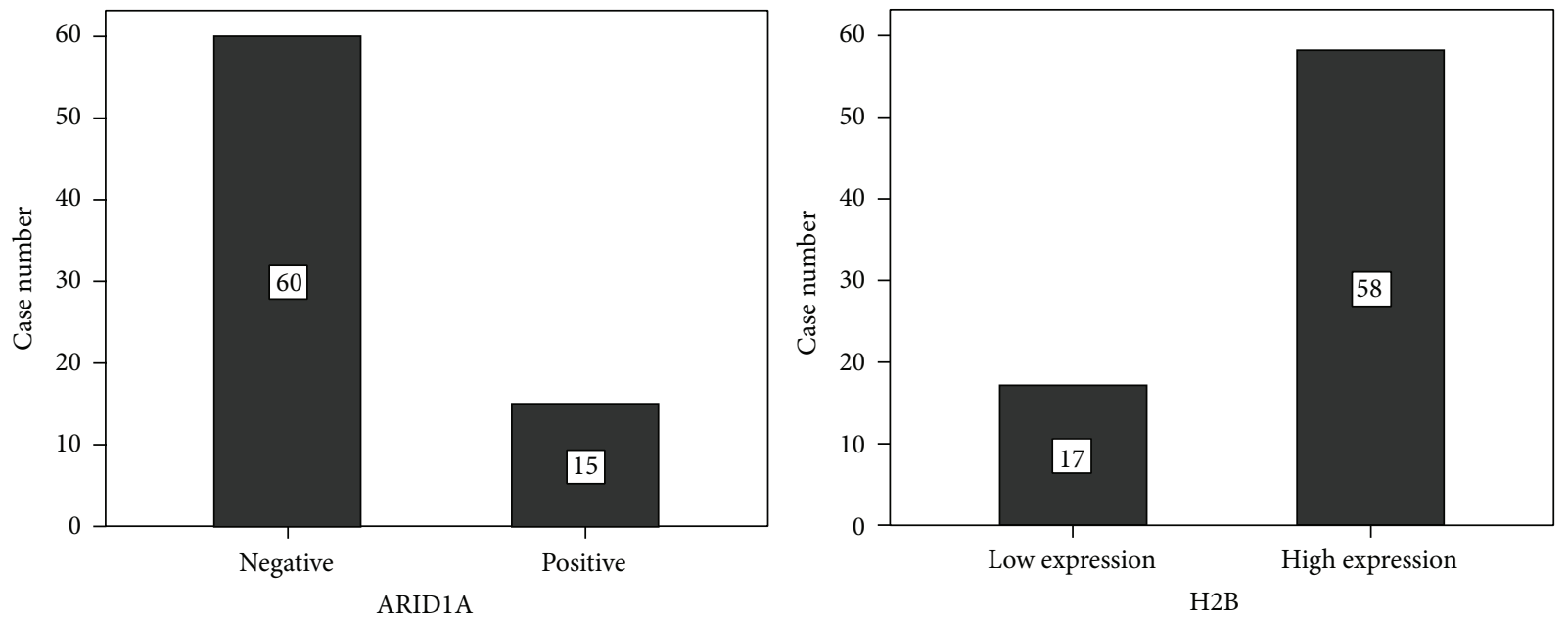

(b)

FIgURE 2: Immunohistochemistry of ARID1A and H2B in breast cancer tissues and corresponding normal tissues. (a) Top: ARID1A was not expressed in normal mammary epithelium and expressed in breast cancer tissue. Down: H2B was expressed in both normal mammary epithelium and breast cancer tissue (100x). (b) Bar chart of immunohistochemical staining results for ARID1A and H2B.

the genomic mutations, whereas the promoter methylation may also be involved in the decline of gene expression [2, $9,24]$. Here, we examined ARID1A protein expression in 75 cases of breast cancer and corresponding normal epithelium. We noticed that the ARID1A protein expression in normal breast epithelium is weak or lost. The expression of ARID1A was found in $20 \%$ cases of breast cancer. The histology of ARID1A positive cases is invasive ductal carcinoma and mucinous carcinoma. By Oncomine database analysis, the expression of ARID1A gene is inconsistent. In TCGA dataset, elevated ARID1A gene expression was found in invasive carcinoma and mucinous carcinoma. TCGA group's finding is consistent with our result. It suggested that ARID1A gene may involve in carcinogenesis in some subtypes of breast cancer.

ARID1A protein is a DNA-binding protein, mainly involved in the regulation of chromatin remodeling in cell nucleus [25]. ARID1A is a member of the ARID family of DNA-binding proteins and a subunit of human SWI/SNFrelated complexes. Histone $\mathrm{H} 2 \mathrm{~B}$ is a main component of 


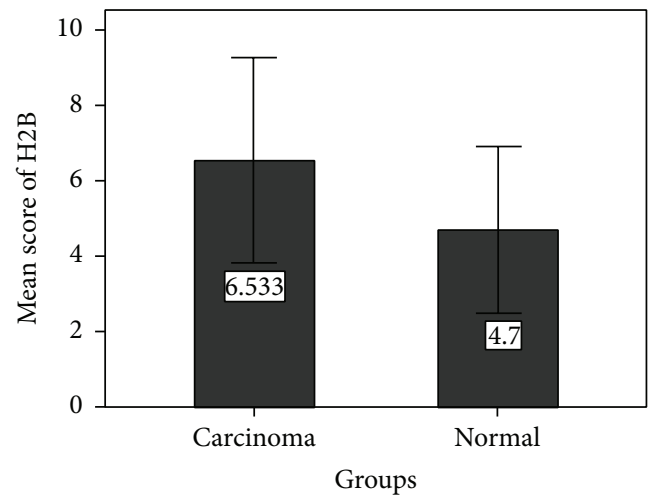

(a)

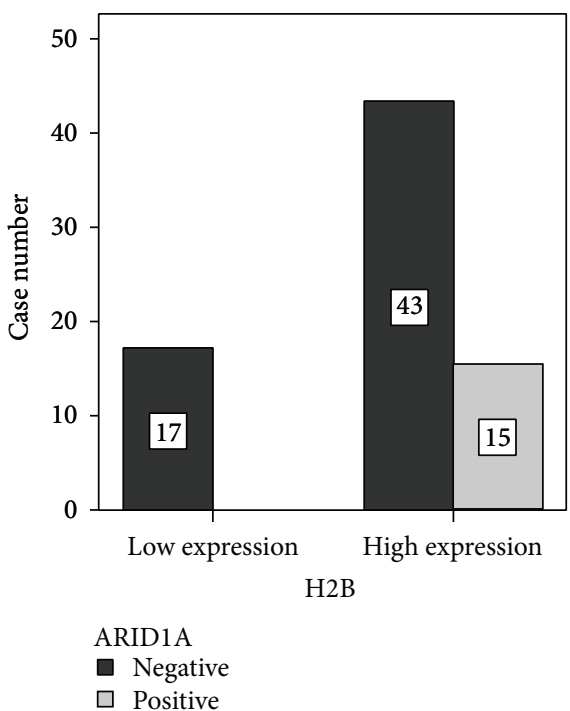

(b)

FIGURE 3: Immunohistochemical scoring and correlation analysis of H2B and ARID1A. (a) The mean score of H2B protein in breast cancer tissues was significantly higher than that in normal mammary epithelium $(P<0.05)$. (b) The protein expressions of ARID1A and H2B are closely related $(P=0.019)$. All 15 cases with ARID1A expression were overlapped with the highly expressed H2B.
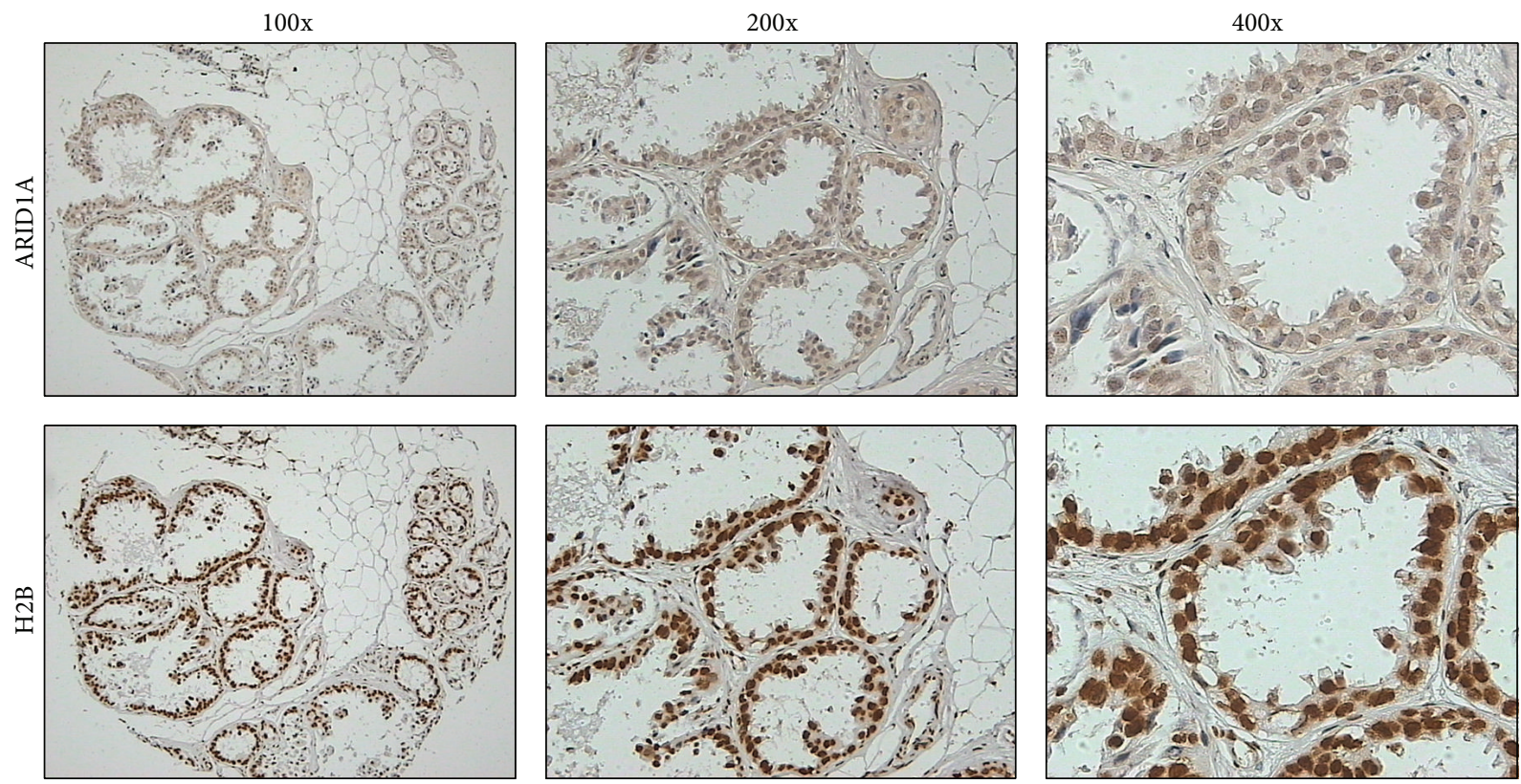

FIGURE 4: The coexpressing observation of ARID1A and H2B protein in one cancer case. Top: ARID1A protein expression in serial section. Down: H2B protein expression in serial sections. Left panel: low power magnification (100x); middle panel: moderate power magnification (200x); right panel: high power magnification (400x).

chromatin. Li and colleagues reported that histone $\mathrm{H} 2 \mathrm{~B}$ is a direct target of ARID1A. ARID1A gene is involved in activation and expression of histone $\mathrm{H} 2 \mathrm{~B}$ through ubiquitin modification [12]. In current study, we firstly analyzed the expressing status and relationship of ARID1A and histone $\mathrm{H} 2 \mathrm{~B}$ in serial sections of tissue microarray. Because the protein expression of ARID1A was limited in $20 \%$ cases of breast cancer, we think that ARID1A may be not master gene in carcinogenesis of breast cancer. It may participate in development of some subtype of breast cancer.

Histone $\mathrm{H} 2 \mathrm{~B}$ is moderately expressed in normal breast epithelium and highly expressed in $70 \%$ cases of breast cancer. However, the precise role of $\mathrm{H} 2 \mathrm{~B}$ protein in breast carcinogenesis is largely unknown. We carefully analyzed the correlation between ARID1A protein expression and $\mathrm{H} 2 \mathrm{~B}$ protein expression and found that all of ARID1A 


\begin{tabular}{|c|c|c|c|c|c|c|c|c|c|c|c|c|c|c|c|c|}
\hline & 1 & 2 & 3 & 4 & 5 & 6 & 7 & 8 & 9 & 10 & 11 & 12 & 13 & 14 & 15 & 16 \\
\hline A & & & & & & & & & & & & & & & & \\
\hline B & A & A & & & & & & & & & & & & & & \\
\hline C & & & & & A & A & & & & & & & & & A & A \\
\hline D & & & & A & A & & & & & & & & & A & A \\
\hline E & & & & & & & & A & A & & & & & & \\
\hline F & & & & & & & & & & & A & A & & & & \\
\hline G & & & A & A & & & A & A & A & A & A & A & & & & \\
\hline H & & & & & & A & A & A & A & & & A & A & & \\
\hline I & & & & & & & & & & & & & & & & \\
\hline J & & & & & & & & & & & A & A & & & & \\
\hline
\end{tabular}

FIGURE 5: The schematic diagram of breast cancer tissue microarray used in current study. Each breast cancer case has two tissue points on the same line. The gray grid in the microarray represented strong positivity for H2B protein. The capital letter A in the grids represented positivity for ARID1A protein. All 15 cases with ARID1A expression were overlapped with the highly expressed H2B.

TABLE 1: Correlation of ARID1A or H2B expression with clinicopathological parameters.

\begin{tabular}{|c|c|c|c|}
\hline Parameters & $\begin{array}{l}\text { ARID1A } \\
\text { positive }\end{array}$ & $\begin{array}{l}\text { ARID1A } \\
\text { negative }\end{array}$ & $P$ value \\
\hline \multicolumn{4}{|l|}{ Age } \\
\hline$<50$ & 6 & 24 & \multirow[t]{2}{*}{1.00} \\
\hline$>51$ & 9 & 36 & \\
\hline \multicolumn{4}{|l|}{ Histology } \\
\hline Invasive tubular cancer & 10 & 41 & \multirow[t]{3}{*}{0.118} \\
\hline Invasive lobular cancer & 3 & 3 & \\
\hline Others & 2 & 16 & \\
\hline \multicolumn{4}{|l|}{ Axillary node } \\
\hline Positive & 7 & 17 & \multirow[t]{2}{*}{0.173} \\
\hline Negative & 8 & 43 & \\
\hline \multicolumn{4}{|l|}{ Location } \\
\hline Left side & 8 & 32 & \multirow[t]{2}{*}{1.00} \\
\hline Right side & 7 & 28 & \\
\hline \multicolumn{4}{|l|}{$\mathrm{H} 2 \mathrm{~B}$ expression } \\
\hline High & 15 & 43 & \multirow[t]{2}{*}{0.019} \\
\hline Low & 0 & 17 & \\
\hline \multirow{2}{*}{ Parameters } & $\mathrm{H} 2 \mathrm{~B}$ & $\mathrm{H} 2 \mathrm{~B}$ & \multirow{2}{*}{$P$ value } \\
\hline & high & low & \\
\hline \multicolumn{4}{|l|}{ Age } \\
\hline$<50$ & 25 & 5 & \multirow[t]{2}{*}{0.311} \\
\hline$>51$ & 33 & 12 & \\
\hline \multicolumn{4}{|l|}{ Histology } \\
\hline Invasive tubular cancer & 42 & 9 & \multirow[t]{3}{*}{0.169} \\
\hline Invasive lobular cancer & 3 & 3 & \\
\hline Others & 13 & 5 & \\
\hline \multicolumn{4}{|l|}{ Axillary node } \\
\hline Positive & 18 & 6 & \multirow[t]{2}{*}{0.741} \\
\hline Negative & 40 & 11 & \\
\hline \multicolumn{4}{|l|}{ Location } \\
\hline Left side & 31 & 9 & \multirow[t]{2}{*}{0.971} \\
\hline Right side & 27 & 8 & \\
\hline \multicolumn{4}{|l|}{ ARID1A expression } \\
\hline Negative & 43 & 17 & \multirow[t]{2}{*}{0.019} \\
\hline Positive & 15 & 0 & \\
\hline
\end{tabular}


TABLE 2: The details of clinical pathological information of breast cancer cases used in the study.

\begin{tabular}{|c|c|c|c|c|c|c|c|c|}
\hline Case number & Age & Location & Cancer types ${ }^{*}$ & Lymph node metastasis & ER expression & PR expression & ARID1A score & H2B score \\
\hline 1 & 74 & Right & IDC & No & Yes & Yes & 0 & 2 \\
\hline 2 & 50 & Left & IDC & Yes & No & Yes & 0 & 6 \\
\hline 3 & 53 & Left & IDC & No & Yes & Yes & 0 & 3 \\
\hline 4 & 41 & Right & IDC & Yes & Yes & Yes & 0 & 0 \\
\hline 5 & 63 & Left & IDC & No & Yes & Yes & 0 & 3 \\
\hline 6 & 48 & Right & IDC & Yes & Yes & Yes & 0 & 0 \\
\hline 7 & 48 & Right & IDC & No & No & Yes & 0 & 6 \\
\hline 8 & 37 & Right & IDC & No & Yes & Yes & 0 & 6 \\
\hline 9 & 74 & Right & IDC & Yes & Yes & Yes & 6 & 6 \\
\hline 10 & 44 & Right & IDC & Yes & No & No & I & 1 \\
\hline 11 & 57 & Right & IDC & Yes & No & Yes & 0 & 9 \\
\hline 12 & 54 & Left & IDC & No & Yes & Yes & 1 & 1 \\
\hline 13 & 66 & Left & IDC & No & Yes & Yes & I & 1 \\
\hline 14 & 37 & Right & IDC & No & Yes & No & 0 & 9 \\
\hline 15 & 48 & Right & IDC & No & Yes & Yes & 0 & 6 \\
\hline 16 & 43 & Left & IDC & No & Yes & Yes & 1 & 1 \\
\hline 17 & 42 & Left & IDC & Yes & Yes & Yes & 0 & 6 \\
\hline 18 & 52 & Left & IDC & Yes & No & Yes & 0 & 6 \\
\hline 19 & 48 & Left & IDC & Yes & Yes & Yes & 3 & 6 \\
\hline 20 & 53 & Left & IDC & No & Yes & Yes & 0 & 9 \\
\hline 21 & 66 & Left & IDC & Yes & Yes & Yes & 0 & 9 \\
\hline 22 & 46 & Right & IDC & Yes & Yes & Yes & 0 & 3 \\
\hline 23 & 63 & Left & IDC & No & Yes & Yes & 0 & 9 \\
\hline 24 & 51 & Left & IDC & No & No & No & 0 & 9 \\
\hline 25 & 53 & Left & IDC & No & Yes & Yes & 0 & 6 \\
\hline 26 & 71 & Left & IDC & No & No & Yes & 0 & 9 \\
\hline 27 & 37 & Right & IDC & Yes & Yes & Yes & 4 & 6 \\
\hline 28 & 77 & Right & IDC & Yes & No & No & 0 & 6 \\
\hline 29 & 59 & Left & IDC & No & No & Yes & 0 & 9 \\
\hline 30 & 58 & Left & IDC & Yes & Yes & Yes & 0 & 9 \\
\hline 31 & 43 & Right & IDC & No & No & No & 0 & 6 \\
\hline 32 & 57 & Left & IDC & No & Yes & Yes & 3 & 9 \\
\hline 33 & 39 & Right & IDC & No & Yes & Yes & 0 & 6 \\
\hline 34 & 57 & Left & IDC & No & No & No & 0 & 9 \\
\hline 35 & 70 & Right & IDC & No & Yes & Yes & 0 & 6 \\
\hline 36 & 47 & Left & IDC & No & No & No & 0 & 9 \\
\hline 37 & 52 & Left & IDC & Yes & Yes & Yes & 6 & 9 \\
\hline 38 & 53 & Right & IDC & Yes & Yes & Yes & 0 & 9 \\
\hline 39 & 45 & Left & IDC & Yes & No & No & 0 & 9 \\
\hline 40 & 42 & Left & IDC & No & Yes & Yes & 0 & 9 \\
\hline 41 & 71 & Left & IDC & No & No & Yes & 0 & 9 \\
\hline 42 & 44 & Right & IDC & No & No & No & 0 & 6 \\
\hline 43 & 53 & Right & IDC & No & No & No & 0 & 4 \\
\hline 44 & 80 & Right & IDC & Yes & Yes & No & 0 & 9 \\
\hline 45 & 44 & Left & IDC & No & No & No & 3 & 9 \\
\hline 46 & 70 & Left & IDC & No & No & No & 3 & 9 \\
\hline 47 & 77 & Right & IDC & No & No & No & 0 & 9 \\
\hline 48 & 51 & Left & IDC & No & No & No & 0 & 4 \\
\hline 49 & 51 & Left & ILC & No & Yes & Yes & 0 & 4 \\
\hline 50 & 46 & Left & ILC & No & Yes & Yes & 6 & 9 \\
\hline 51 & 62 & Right & ILC & No & Yes & No & 0 & 4 \\
\hline
\end{tabular}


TABLE 2: Continued.

\begin{tabular}{|c|c|c|c|c|c|c|c|c|}
\hline Case number & Age & Location & Cancer types* & Lymph node metastasis & ER expression & PR expression & ARID1A score & H2B score \\
\hline 52 & 39 & Right & ILC & No & Yes & Yes & 6 & 9 \\
\hline 53 & 38 & Left & ILC & No & Yes & Yes & 3 & 9 \\
\hline 54 & 59 & Left & IDC & Yes & Yes & Yes & 3 & 9 \\
\hline 55 & 45 & Left & MUC & No & No & Yes & 0 & 9 \\
\hline 56 & 63 & Left & MUC & No & Yes & Yes & 0 & 6 \\
\hline 57 & 49 & Right & MUC & No & No & No & 0 & 6 \\
\hline 58 & 48 & Left & IDC & No & No & No & 0 & 6 \\
\hline 59 & 50 & Right & IDC & No & No & Yes & 0 & 9 \\
\hline 60 & 57 & Right & IDC & Yes & Yes & Yes & 4 & 6 \\
\hline 61 & 81 & Right & MUC & No & Yes & No & 3 & 9 \\
\hline 62 & 80 & Left & MUC & No & Yes & Yes & 0 & 6 \\
\hline 63 & 60 & Right & MUC & No & Yes & No & 4 & 6 \\
\hline 64 & 65 & Right & MUC & No & Yes & Yes & 0 & 6 \\
\hline 65 & 66 & Right & MUC & No & Yes & Yes & 0 & 0 \\
\hline 66 & 65 & Right & MUC & No & Yes & Yes & 0 & 9 \\
\hline 67 & 50 & Left & MEC & No & No & No & 0 & 0 \\
\hline 68 & 44 & Left & MEC & No & No & No & 0 & 6 \\
\hline 69 & 74 & Right & MEC & No & Yes & Yes & 0 & 9 \\
\hline 70 & 33 & Left & MEC & No & No & Yes & 0 & 9 \\
\hline 71 & 51 & Left & LRC & Yes & No & No & 0 & 3 \\
\hline 72 & 55 & Left & LRC & No & No & No & 0 & 2 \\
\hline 73 & 56 & Right & LRC & Yes & No & No & 0 & 2 \\
\hline 74 & 70 & Left & DCI & No & Yes & Yes & 0 & 9 \\
\hline 75 & 65 & Right & DCI & No & Yes & Yes & I & I \\
\hline 76 & 45 & Right & DCI & No & Yes & Yes & 0 & 9 \\
\hline 77 & 41 & Left & ILC & Yes & Yes & Yes & 0 & 3 \\
\hline 78 & 79 & Right & IDC & Yes & Yes & Yes & 3 & 9 \\
\hline 79 & 74 & Right & IDC & Yes & No & Yes & 0 & 6 \\
\hline 80 & 51 & Left & IDC & No & No & No & 0 & 3 \\
\hline
\end{tabular}

* IDC: invasive ductal carcinoma; ILC: invasive lobular carcinoma; MUC: mucinous carcinoma; MEC: medullary carcinoma; LRC: lipid-rich carcinoma; DCI: ductal carcinoma in situ.

expressing cases are accompanied by high expression of $\mathrm{H} 2 \mathrm{~B}$ protein. The coexpression of ARID1A and H2B suggested that ARID1A may be involved in the histone modification in some subtypes of breast cancer. However, the exact role of $\mathrm{H} 2 \mathrm{~B}$ in breast cancer is not clear yet. Our data revealed that H2B high expression is frequent in breast cancers, and we need to investigate the role of $\mathrm{H} 2 \mathrm{~B}$ in breast cancer further.

\section{Conflict of Interests}

The authors declare no competing financial interests.

\section{Authors' Contribution}

Yan $\mathrm{Wu}$ designed and performed the experiments. Yan $\mathrm{Gu}$, Shanyu Guo, and Qiancheng Dai contributed the reagents, materials, and analysis tools. Wei Zhang analyzed the data and wrote the paper.

\section{Acknowledgments}

This work was partly supported by National Natural Science Foundation of China (81572760) and the Natural Science Foundation of Science and Technology Commission of Shanghai City (14ZR1424400 and 14411950200).

\section{References}

[1] Z. J. Zang, I. Cutcutache, S. L. Poon et al., "Exome sequencing of gastric adenocarcinoma identifies recurrent somatic mutations in cell adhesion and chromatin remodeling genes," Nature Genetics, vol. 44, no. 5, pp. 570-574, 2012.

[2] S. Jones, M. Li, D. W. Parsons et al., "Somatic mutations in the chromatin remodeling gene ARID1A occur in several tumor types," Human Mutation, vol. 33, no. 1, pp. 100-103, 2012.

[3] J. Huang, Q. Deng, Q. Wang et al., "Exome sequencing of hepatitis B virus-associated hepatocellular carcinoma," Nature Genetics, vol. 44, no. 10, pp. 1117-1121, 2012. 
[4] K. Wang, J. Kan, S. T. Yuen et al., "Exome sequencing identifies frequent mutation of ARID1A in molecular subtypes of gastric cancer," Nature Genetics, vol. 43, no. 12, pp. 1219-1223, 2011.

[5] Y. Gui, G. Guo, Y. Huang et al., "Frequent mutations of chromatin remodeling genes in transitional cell carcinoma of the bladder," Nature Genetics, vol. 43, no. 9, pp. 875-878, 2011.

[6] S. Jones, T.-L. Wang, I.-M. Shih et al., "Frequent mutations of chromatin remodeling gene ARID1A in ovarian clear cell carcinoma," Science, vol. 330, no. 6001, pp. 228-231, 2010.

[7] J. N. Wu and C. W. M. Roberts, "ARID1A mutations in cancer: another epigenetic tumor suppressor?" Cancer Discovery, vol. 3, no. 1, pp. 35-43, 2013.

[8] B. Guan, M. Gao, C.-H. Wu, T.-L. Wang, and I.-M. Shih, "Functional analysis of in-frame indel ARID1A mutations reveals new regulatory mechanisms of its tumor suppressor functions," Neoplasia, vol. 14, no. 10, pp. 986-993, 2012.

[9] X. Zhang, Q. Sun, M. Shan et al., "Promoter hypermethylation of ARID1A gene is responsible for its low mRNA expression in many invasive breast cancers," PLoS ONE, vol. 8, no. 1, Article ID e53931, 2013.

[10] A. Patsialou, D. Wilsker, and E. Moran, "DNA-binding properties of ARID family proteins," Nucleic Acids Research, vol. 33, no. 1, pp. 66-80, 2005.

[11] N. G. Nagl Jr., A. Patsialou, D. S. Haines, P. B. Dallas, G. R. Beck Jr., and E. Moran, "The p270 (ARID1A/SMARCF1) subunit of mammalian SWI/SNF-related complexes is essential for normal cell cycle arrest," Cancer Research, vol. 65, no. 20, pp. 9236-9244, 2005.

[12] X. S. Li, P. Trojer, T. Matsumura, J. E. Treisman, and N. Tanese, "Mammalian SWI/SNF-a subunit BAF250/ARID1 is an E3 ubiquitin ligase that targets histone H2B," Molecular and Cellular Biology, vol. 30, no. 7, pp. 1673-1688, 2010.

[13] Y. Urasaki, L. Heath, and C. W. Xu, "Coupling of glucose deprivation with impaired histone $\mathrm{H} 2 \mathrm{~B}$ monoubiquitination in tumors," PLoS ONE, vol. 7, no. 5, Article ID e36775, 2012.

[14] J. Slowinski, U. Mazurek, G. Bierzynska-Macyszyn et al., "Cell proliferative activity estimated by histone H2B mRNA level correlates with cytogenetic damage induced by radiation in human glioblastoma cell lines," Journal of Neuro-Oncology, vol. 71, no. 3, pp. 237-243, 2005.

[15] Y. Hao, Y. Yu, L. Wang et al., "IPO-38 is identified as a novel serum biomarker of gastric cancer based on clinical proteomics technology," Journal of Proteome Research, vol. 7, no. 9, pp. 36683677, 2008.

[16] D. R. Rhodes, J. Yu, K. Shanker et al., "ONCOMINE: a cancer microarray database and integrated data-mining platform," Neoplasia, vol. 6, no. 1, pp. 1-6, 2004.

[17] D. R. Rhodes, S. Kalyana-Sundaram, V. Mahavisno et al., "Oncomine 3.0: genes, pathways, and networks in a collection of 18,000 cancer gene expression profiles," Neoplasia, vol. 9, no. 2, pp. 166-180, 2007.

[18] D. R. Rhodes, S. Kalyana-Sundaram, V. Mahavisno, T. R. Barrette, D. Ghosh, and A. M. Chinnaiyan, "Mining for regulatory programs in the cancer transcriptome," Nature Genetics, vol. 37, no. 6, pp. 579-583, 2005.

[19] X.-J. Ma, S. Dahiya, E. Richardson, M. Erlander, and D. C. Sgroi, "Gene expression profiling of the tumor microenvironment during breast cancer progression," Breast Cancer Research, vol. 11, no. 1, article R7, 2009.

[20] L. Radvanyi, D. Singh-Sandhu, S. Gallichan et al., "The gene associated with trichorhinophalangeal syndrome in humans is overexpressed in breast cancer," Proceedings of the National Academy of Sciences of the United States of America, vol. 102, no. 31, pp. 11005-11010, 2005.

[21] S. Glück, C. Germond, P. Lopez et al., "A phase I trial of high-dose paclitaxel, cyclophosphamide and mitoxantrone with autologous blood stem cell support for the treatment of metastatic breast cancer," European Journal of Cancer, vol. 34, no. 7, pp. 1008-1014, 1998.

[22] H. Zhao, A. Langerød, Y. Ji et al., "Different gene expression patterns in invasive lobular and ductal carcinomas of the breast," Molecular Biology of the Cell, vol. 15, no. 6, pp. 2523-2536, 2004.

[23] A. L. Richardson, Z. C. Wang, A. De Nicolo et al., "X chromosomal abnormalities in basal-like human breast cancer," Cancer Cell, vol. 9, no. 2, pp. 121-132, 2006.

[24] A. Mamo, L. Cavallone, S. Tuzmen et al., "An integrated genomic approach identifies ARID1A as a candidate tumorsuppressor gene in breast cancer," Oncogene, vol. 31, no. 16, pp. 2090-2100, 2012.

[25] X. Zhang, Y. Zhang, Y. Yang et al., "Frequent low expression of chromatin remodeling gene ARID1A in breast cancer and its clinical significance," Cancer Epidemiology, vol. 36, no. 3, pp. 288-293, 2012. 


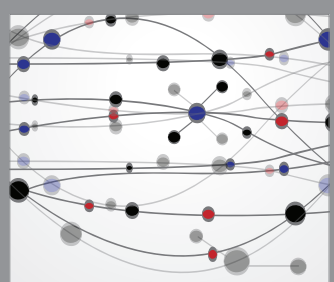

The Scientific World Journal
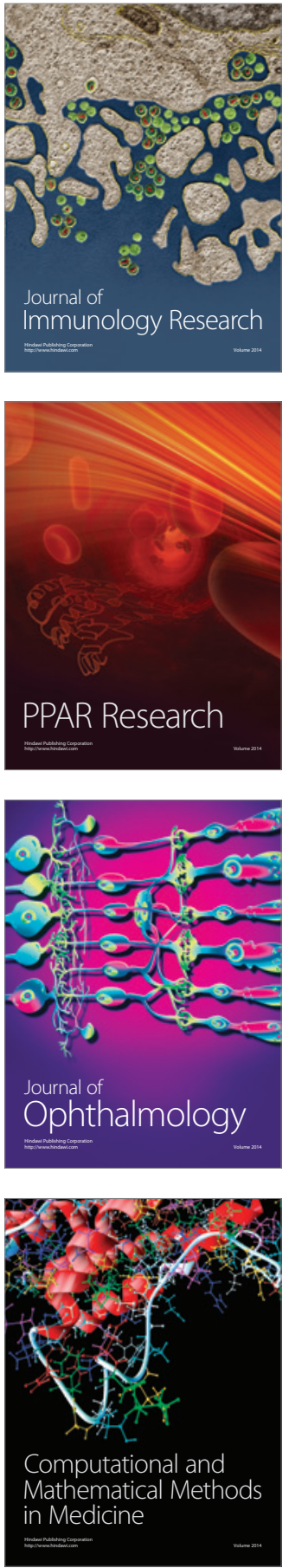

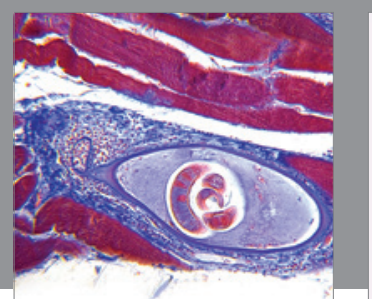

Gastroenterology Research and Practice

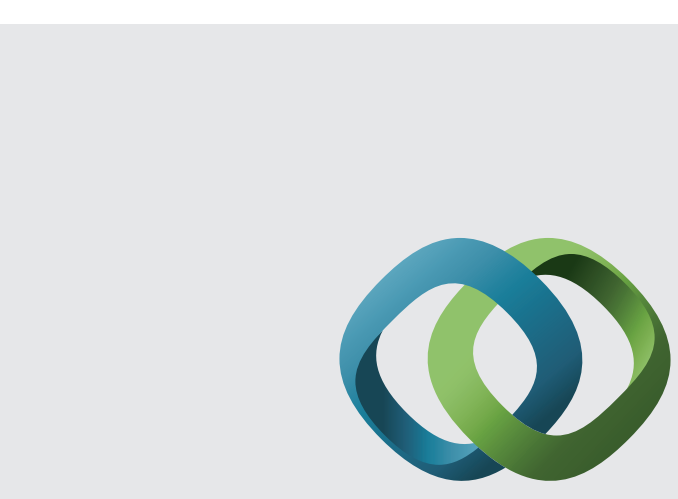

\section{Hindawi}

Submit your manuscripts at

http://www.hindawi.com
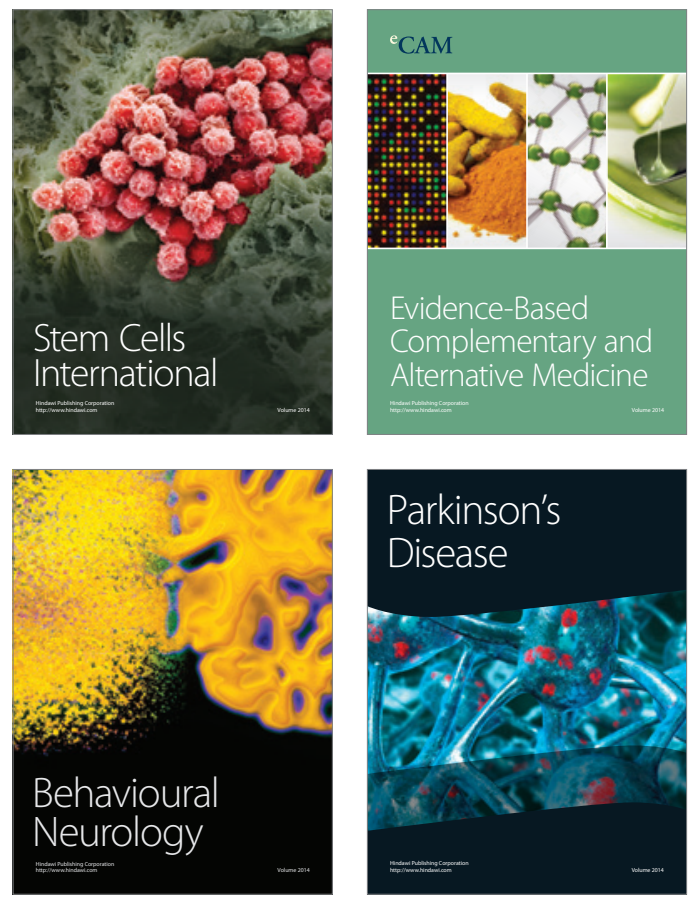
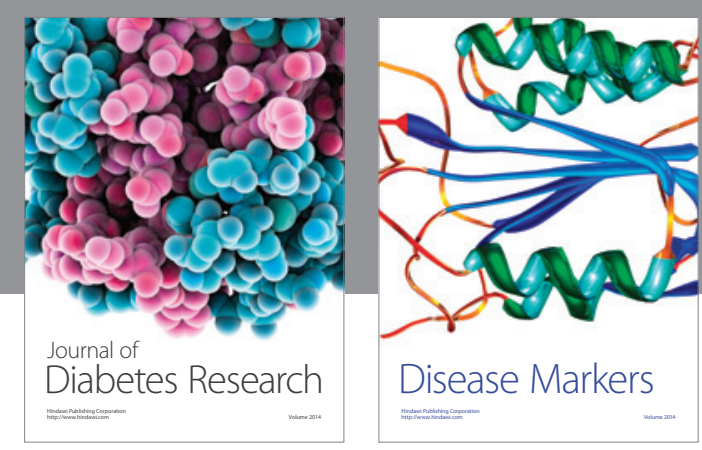

Disease Markers
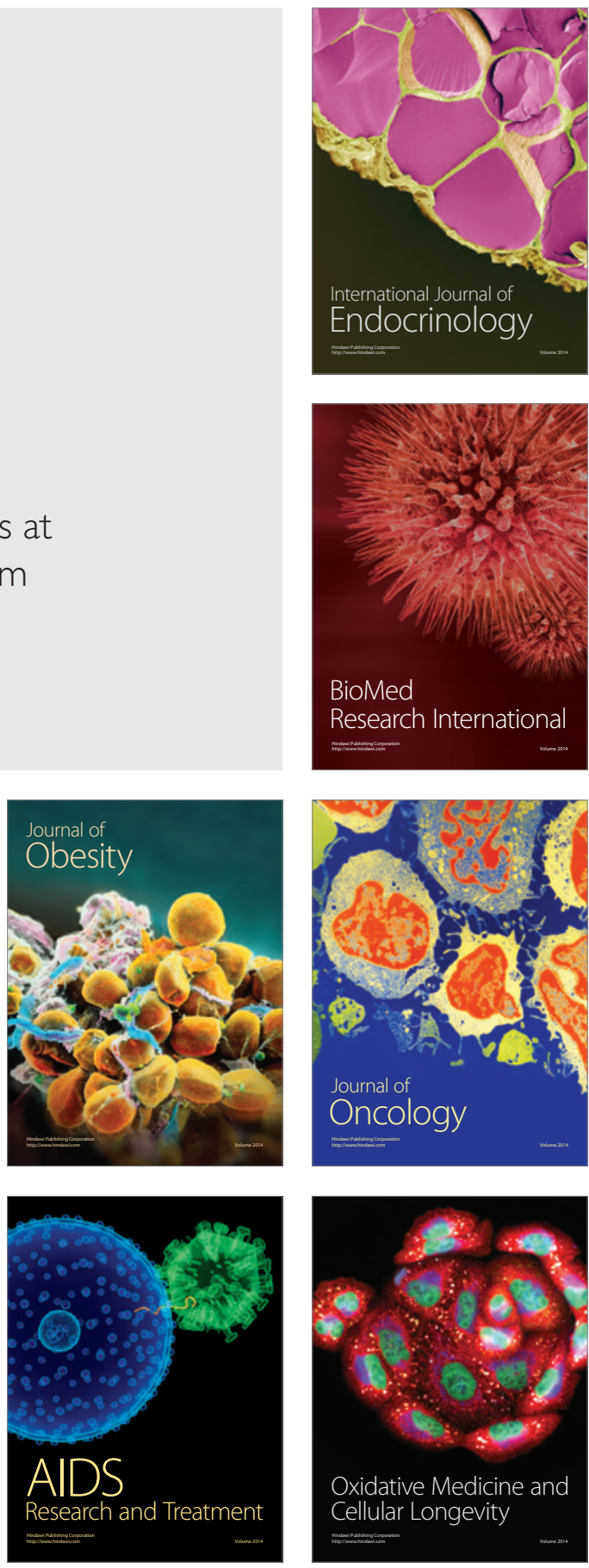